Table 1. (Continued)

\begin{tabular}{|c|c|c|}
\hline Characteristic & No. $(\mathrm{N}=65)$ & $\%$ \\
\hline Urinary tract infection & 14 & 21.5 \\
\hline Skin soft-tissue infection & 8 & 12.4 \\
\hline Gum infection & 4 & 6.2 \\
\hline Others & 2 & 3.1 \\
\hline Antiviral treatment & 46 & 70.8 \\
\hline Glucocorticoid treatment & 25 & 38.5 \\
\hline Pathogen isolates & 43 & \\
\hline Coagulase negative staphylococcus & 12 & 27.9 \\
\hline Acinetobacter & 9 & 20.9 \\
\hline Pseudomonas aeruginosa & 6 & 14.0 \\
\hline Enterococcus faecium & 5 & 11.6 \\
\hline Klebsiella pneumoniae & 4 & 9.3 \\
\hline Escherichia coli & 2 & 4.6 \\
\hline Candida albicans & 2 & 4.6 \\
\hline Mucor & 2 & 4.6 \\
\hline Other & 1 & 2.3 \\
\hline Mortality & 10 & 15.4 \\
\hline
\end{tabular}

Note. IQR, interquartile range.

Table 1. Significant positive associations between nosocomial infection and the following were detected by univariate analysis: diabetes, hematological disease, invasive devices (central venous catheter [CVC] or peripherally inserted central catheter [PICC]), combination of antibiotics, and glucocorticoid treatment. Among these factors, the highest odds ratio was for invasive devices (OR, 4.62; 95\% CI, 2.47-8.62) followed by diabetes (OR, 3.04; 95\% CI, 1.38-6.69), combination of antibiotics (OR, 3.02; 95\% CI, 1.10-8.26), glucocorticoid treatment (OR, 2.44; 95\% CI, 1.36-4.37), and hematological disease (OR, 1.95; 95\% CI, 1.01-1.06).

For multivariable analysis, the dependent variable was nosocomial infection status and independent variables were all factors that demonstrated statistical significance, as mentioned with univariate analysis. Significant predictors of nosocomial infection after adjustment for other covariates were invasive devices (OR, 4.28; 95\% CI, 2.47-8.61; $P=.007$ ) followed by diabetes (OR,: 3.06, 95\% CI, 1.41-7.22; $P=.037)$, and combination of antibiotics (OR, 1.84, 95\% CI, 1.31-4.59; $P=.003$ ) (Supplementary Table 1 online).

In conclusion, these findings suggest that nosocomial infections are common among patients with COVID-19 and can be predicted by considering certain risk factors. Rational utilization of antibiotics and steroids to treat patients with COVID-19 is important in preventing nosocomial infection, and special attention should be given to diabetic patients and patients with invasive devices (ie, CVC or PICC). Future studies are warranted to evaluate the efficacy of implementing infection control strategies or protocols on COVID-19 patients to achieve better therapeutic outcomes.

\section{Acknowledgments. None.}

Financial support. This work was financially supported by the National Natural Science Foundation of China (grant no. 81803387) and the Hubei Provincial Natural Science Foundation of China (grant no. 2018CFB152).

Conflicts of interest. All authors report no conflicts of interest relevant to this article.

\section{References}

1. Chen N, Zhou M, Dong X, et al. Epidemiological and clinical characteristics of 99 cases of 2019 novel coronavirus pneumonia in Wuhan, China: a descriptive study. Lancet 2020;395:507-513.

2. Ruan Q, Yang K, Wang W, Jiang L, Song J. Clinical predictors of mortality due to COVID-19 based on an analysis of data of 150 patients from Wuhan, China. Intensive Care Med 2020 [Epub ahead of print]. doi: 10.1007/s00134020-05991-x.

3. Diagnosis and treatment protocol for novel coronavirus pneumonia, trial version 7. World Health Organization website. https://www.who.int/docs/ default-source/wpro-documents/countries/china/covid-19-briefing-nhc/ 1-clinical-protocols-for-the-diagnosis-and-treatment-of-covid-19-v7.pdf? sfvrsn=c6cbfba4_2. Published March 3, 2020. Accessed April 15, 2020.

\title{
SARS-CoV-2: The Lombardy scenario in numbers
}

\author{
Andrea Molinari $M D^{1}$ (10), Federico Pistoia $M D^{1}$ and Giuditta Antonelli JD ${ }^{2}$ \\ ${ }^{1}$ Department of Health Sciences (DISSAL), University of Genova, Genoa, Italy and ${ }^{2}$ University of Genova, Genoa, Italy
}

To the Editor-On March 11, 2020, the World Health Organization (WHO) declared the spread of severe acute respiratory syndrome coronavirus 2 (SARS-CoV-2) to constitute a pandemic of COVID-19 infectious disease. ${ }^{1}$ On February 20, 2020, the first national cluster in Italy was identified in the Lombardy region

Author for correspondence: Andrea Molinari, Email: a.molinari@live.it

Cite this article: Molinari A, Pistoia F, and Antonelli G. (2020). SARS-CoV-2: The Lombardy scenario in numbers. Infection Control \& Hospital Epidemiology, 41: 983-984, https://doi.org/10.1017/ice.2020.115 after the diagnosis of SARS-CoV-2 in a 38-year-old man with a severe pneumonia and no relevant exposure history. ${ }^{2}$ To date, 74,386 SARS-CoV-2 laboratory-confirmed cases have been reported in Italy, with 32,346 cases in Lombardy alone, by far the most affected region. ${ }^{3}$

Given the extent of the phenomenon, we must urgently consider how the rapid spread of the infection can overload the National Health Service (SSN) and affect the mortality rate. The SSN is regarded as a high-level healthcare service, and it is regionally 
based. ${ }^{4}$ Specifically, Lombardy's healthcare service is considered a benchmark in terms of quality and efficiency. ${ }^{5}$

In Lombardy, region of $\sim 10$ million people, the pre-crisis total intensive care unit (ICU) bed capacity was of $\sim 720$ beds, with a mean occupancy rate in the winter months of $85 \%-90 \%{ }^{2}$ To deal with SARS-CoV-2 outbreak, the number of ICU beds has significantly increased, and several departments have been reorganized and dedicated exclusively to COVID-19 patients. Nonetheless, hospitals in Lombardy are dramatically overcrowded with lack of medications, mechanical ventilators, oxygen, and personal protective equipment (PPE). ${ }^{6}$ Clearly, the increased number of cases is posing a serious threat to the entire SSN. ${ }^{7}$

We believe that the following numbers regarding the Lombardy region help to fully measure and elucidate the medical and social impact of SARS-CoV-2 outbreak.

The Italian National Institute of Health (ISS) reported that 4,451 people died in Lombardy due to SARS-CoV-2 complications between January 3 and March 25, 2020. ${ }^{3}$ In March 2019, there were 9,062 deaths, with 292 deaths per day ${ }^{8}$; in March 2020, the number of deaths per day was exceeded for 8 days by the number of deaths of confirmed COVID-19 patients alone. The most deadly day was March 21, with 546 daily fatalities due to COVID-19.

To date, 11,262 COVID-19 patients have been hospitalized1,236 in an ICU. More than 5,000 healthcare workers have been infected across Italy, accounting for $9 \%$ of total cases. This number particularly reflects the lack of PPE and the unexpected pressure on the SSN. ${ }^{3}$

This report highlights how the impact and the consequences of the COVID-19 pandemic have been largely underestimated in Western countries, and it raises concerns about the potential responsiveness of healthcare systems in less-developed countries.

\section{Acknowledgments.}

Financial support. No financial support was provided relevant to this article.

Conflicts of interest. All authors report no conflicts of interest relevant to this article.

\section{References}

1. WHO virtual press conference on COVID-19-11 March 2020. World Health Organization website. https://www.who.int/docs/default-source/coronaviruse/ transcripts/who-audio-emergencies-coronavirus-press-conference-full-and-final11mar2020.pdf?sfvrsn=cb432bb3_2. Published 2020. Accessed March 23, 2020.

2. Onder G, Rezza G, Brusaferro S. Case-fatality rate and characteristics of patients dying in relation to COVID-19 in Italy. JAMA 2020 [Epub ahead of print]. doi: 10.1001/jama.2020.4683

3. COVID-19 Surveillance Group-Istituto Superiore di Sanità. Epicentro website. https://www.epicentro.iss.it/coronavirus/sars-cov-2-sorveglianza-dati. Published 2020. Accessed March 25, 2020.

4. Christopher JL, Murray JA, Lauer DB, et al. Measuring overall health system performance for 191 countries. World Health Organization website. https://www.who.int/healthinfo/paper30.pdf. Published 2011. Accessed March 24, 2020.

5. Bosio M, Meroni P. Quality and efficiency of the health service in the Italian region of Lombardy. G Ital Nefrol 2002;19(Spec No. 21):S28-S32.

6. Nacoti M, Ciocca A, Giupponi A, et al. At the epicenter of the COVID-19 pandemic and humanitarian crises in Italy: changing perspectives on preparation and mitigation. NEJM Cathalyst Innov Care Deliv 2020;1(2) [Epub ahead of print]. doi: 10.1056/CAT.20.0080.

7. Saglietto A, D'Ascenzo F, Zoccai GB, et al. COVID-19 in Europe: the Italian lesson. Lancet 2020 [Epub ahead of print]. doi: 10.1016/S0140-6736 (20)30690-5.

8. Istituto nazionale di statistica (ISTAT), Statistiche demografiche website. http://demo.istat.it/bilmens2019gen/index.html. Published 2019. Accessed March 24, 2020.

\title{
The largest epicenter of the coronavirus outbreak in Vietnam
}

\author{
Trang H.D. Nguyen ${ }^{1,2}$ and Danh C. $\mathrm{Vu}^{3}$ (1) \\ ${ }^{1}$ Institute of Biotechnology and Food Technology, Industrial University of Ho Chi Minh City, Vietnam, ${ }^{2}$ Food for Health Center, University of Nebraska, Lincoln, \\ Nebraska, United States and ${ }^{3}$ Faculty of Technology, Van Lang University, Ho Chi Minh City, Vietnam
}

To the Editor-As of April 1, the total number of SARS-Cov2-positive cases in Vietnam reached 218, and 37 of these were infected within a public hospital in Hanoi, the capital of Vietnam. ${ }^{1}$ Thus far, this hospital is the largest COVID-19 hotspot in the country.

Three patterns of transmission occurred in the hospital: (1) between healthcare workers (HCWs), (2) from COVID-19 patients to HCWs, and (3) from nonclinical hospital staff to others. Figure 1 illustrates a timeline of the spread of the SARS-Cov-2 virus within the hospital from the first confirmed case on March 20 to the most

\footnotetext{
Author for correspondence: Danh C. Vu, E-mail: dcvgwc@mail.missouri.edu

Cite this article: Nguyen THD and Vu DC. (2020). The largest epicenter of the coronavirus outbreak in Vietnam. Infection Control \& Hospital Epidemiology, 41: 984-985, https://doi.org/10.1017/ice.2020.128
}

recent case on April 1. The first SARS-Cov-2-positive case was a medical worker (P87), who was in close contact with a SARSCov-2-infected nurse (P86). ${ }^{2}$ With the exception of the 2 infected cases, P86 and P28, who contracted the coronavirus from the outside, no HCW, non-COVID-19 inpatients, or visitors had tested positive for the coronavirus. Since March 28, SARS-CoV-2 infections among nonclinical staff have emerged, and subsequently, 25 of the 37 COVID-19 cases (68\%) were nonclinical staff working in the dining hall of the hospital. These catering workers were responsible for preparing meals and delivering food and hot water to patients and visitors across the hospital daily, and it is likely that these nonclinical staff are the main contributors to the spread of the virus within the hospital. Healthcare-associated infection is known characteristic of coronavirus-related diseases and a leading route of transmission. ${ }^{3}$ 